05,06

\title{
Температурные изменения магнитной структуры мультиферроика $\mathrm{BiFe}_{0.80} \mathrm{Cr}_{0.20} \mathrm{O}_{3}$
}

\author{
(C) В.С. Русаков ${ }^{1}$, В.С. Покатилов 2 ॠ, А.С. Сигов ${ }^{2}$, А.А. Белик ${ }^{3}$, М.Е. Мацнев ${ }^{1}$ \\ ${ }^{1}$ Московский государственный университет им. М.В. Ломоносова, \\ Москва, Россия \\ ${ }^{2}$ МИРЭА - Российский технологический университет, \\ Москва, Россия \\ ${ }^{3}$ National Institute for Materials Science (NIMS), \\ Tsukuba, Japan \\ ฯ E-mail: pokatilov@mirea.ru
}

Поступила в Редакцию 20 декабря 2018 г.

В окончательной редакции 20 декабря 2018 г.

Принята к публикации 27 декабря 2018 г.

Представлены результаты мёссбауэровских исследований магнитной структуры мультиферроика $\mathrm{BiFe}_{0.80} \mathrm{Cr}_{0.20} \mathrm{O}_{3}$ в области температур 5-550 K. Обнаружено, что при температурах ниже $260 \mathrm{~K}$ в $\mathrm{BiFe}_{0.80} \mathrm{Cr}_{0.20} \mathrm{O}_{3}$ существует коллинеарная антиферромагнитная структура $G$-типа. Выше температуры $260 \mathrm{~K}$ возникает ангармоническая спиновая волна с магнитной анизотропией типа „легкая ось“ с высоким значением параметра ангармонизма. При дальнейшем повышении температуры параметр $m$ уменьшается и стремится к нулю при $T \sim 420 \mathrm{~K}$, при которой реализуется гармоническая спиновая волна. Выше температуры $420 \mathrm{~K}$ параметр $m$ снова увеличивается, спиновая волна становится ангармонической с магнитной анизотропией типа „легкая плоскость“. При температуре Нееля $T_{N}=505 \pm 10 \mathrm{~K}$ образец переходит из магнитоупорядоченного в парамагнитное состояние. Изменение типа магнитной анизотропии при $T \sim 420 \mathrm{~K}$ объясняется конкуренцией разного знака вкладов в эффективную константу магнитной анизотропии и их различной зависимостью от температуры для мультиферроика $\mathrm{BiFe}_{0.80} \mathrm{Cr}_{0.20} \mathrm{O}_{3}$.

Работа выполнена при поддержке РФФИ (грант № 14-02-01109а и № 17-02-00911а) и Министерства науки и высшего образования РФ (госзадание № 3.1489.2017/4.6).

DOI: 10.21883/FTT.2019.06.47686.340

\section{1. Введение}

Мультиферроики на основе $\mathrm{BiFeO}_{3}$ представляют огромный интерес как для фундаментальных исследований, так и практических применений. Феррит висмута является сегнетомагнетиком, обладающим высокими температурами магнитного (температура Нееля $T_{N}=640 \mathrm{~K}$ ) и электрического упорядочения (температура образования полярной фазы $\left.T_{C}=1120 \mathrm{~K}[1]\right)$. В феррите висмута методом нейтронографии была обнаружена пространственная спин-модулированная структура (ПСМС) [2], а в работах [3,4] дано теоретическое обоснование существования этой структуры. В работах $[5,6]$ методом ядерного магнитного резонанса (ЯМР) было подтверждено существование ПСМС в $\mathrm{BiFeO}_{3}$. Методом нейтронографии в работе [7] удалось установить, что в $\mathrm{BiFeO}_{3}$ при $4.2 \mathrm{~K}$ ПСМС ангармоническая, и оценить параметр ангармонизма $m \leq 0.25$. В работе [8] был измерен параметр ангармонизма методами ЯМР при $4.2 \mathrm{~K}(m=0.25 \pm 0.07)$ и мессбауэровской спектроскопии при $4.85 \mathrm{~K}(m=0.26 \pm 0.06)$.

ПСМС усредняет намагниченность феррита висмута и, следовательно, снижает магнитоэлектрический коэффициент. Наличие ПСМС значительно усложняет применение феррита $\mathrm{BiFeO}_{3}$ для прикладных применений.
Допирование феррита висмута примесными $s$-, $p$ - и $d$-атомами, в позициях атомов висмута и железа, приводит к заметному улучшению магнитных и электрических свойств (см., например, [9]). В большинстве работ предполагалось, что одна из основных причин улучшения магнитных и электрических свойств допированных ферритов обусловлена разрушением пространственной спин-модулированной структуры (ПСМС). Чтобы установить существование ПСМС и определить ее параметры в мультиферроиках на основе $\mathrm{BiFeO}_{3}$, необходимы экспериментальные методы, которые позволяют наблюдать и диагностировать эту структуру. Такими методами являются нейтронография $[2,3,6]$, ядерный магнитный резонанс [4-6] и мессбауэровская спектроскопия (MC) [6]. Исследований локальной магнитной структуры и ПСМС в мультиферроиках на основе феррита висмута, содержащих примесные $s$-, $p$ - и $d$-атомами, этими методами очень мало.

В литературе известны лишь несколько работ, в которых были изучены наряду со сверхтонкими взаимодействиями (СТВ) ядер ${ }^{57} \mathrm{Fe}$, ПСМС и измерены параметры ангармонизма $m$ в зависимости от состава и температуры в $\mathrm{BiFeO}_{3}$ и некоторых мультиферроиках на его основе. Исследование влияния замещения атомов железа примесными $3 d$-атомами в ферритах $\mathrm{BiFe}_{0.95} T_{0.05} \mathrm{O}_{3}$ 
$(T=\mathrm{Sc}, \mathrm{Mn}, \mathrm{Cr})$ и $\mathrm{BiFe}_{1-x} \mathrm{Cr}_{x} \mathrm{O}_{3}(x=0-0.20)$ на ПСМС методом мессбауэровской спектроскопии проведены в работах [10-13]. При замещении трехвалентных катионов железа трехвалентными катионами хрома в мультиферроиках $\mathrm{BiFe}_{1-x} \mathrm{Cr}_{x} \mathrm{O}_{3}(x=0-0.20)$ при комнатной температуре наблюдается усиление ангармонизма пространственной спин-модулированной структуры (ПСМС) [10]. При комнатной температуре параметр ангармонизма $m$ увеличивается при допировании феррита $\mathrm{BiFeO}_{3}$ примесными атомами $\mathrm{Sc}$ и $\mathrm{Mn}$.

Влияние температуры на СТВ и ПСМС (в том числе на параметр ангармонизма $m$ ) в мультиферроике $\mathrm{BiFeO}_{3}$ исследовано в работах $[14,15]$ методом мессбауэровской спектроскопии на ядрах ${ }^{57} \mathrm{Fe}$. Было обнаружено, что в области температур 4.8-300 K при увеличении температуры параметр ангармонизма $m$ уменьшается от $m=0.26$ до 0.15 , становится равным нулю при $330 \mathrm{~K}$ и затем при дальнейшем росте температуры увеличивается до $m=0.47$. При температуре $T \approx 330 \mathrm{~K}$ изменяется знак эффективной константы магнитной анизотропии $K_{u}$ с положительного в области температур $T<330 \mathrm{~K}$ на отрицательный в области $T>330 \mathrm{~K}$. При $T \approx 330 \mathrm{~K}$ происходит изменение типа магнитной анизотропии с „легкой оси“ при $T<330 \mathrm{~K}$ на ,легкую плоскость“ при $T>330 \mathrm{~K}$. При $T \approx 330 \mathrm{~K}$ параметр ангармонизма $m=0$ и реализуется гармоническая спиновая волна.

В работе [12] были представлены результаты мёссбауэровских исследований на ядрах ${ }^{57} \mathrm{Fe}$ в мультиферроике $\mathrm{BiFe}_{0.95} \mathrm{Cr}_{0.05} \mathrm{O}_{3}$ в диапазоне температур $5.2-300 \mathrm{~K}$. Обнаружено, что при замещении катионов $\mathrm{Fe}$ на катионы $\mathrm{Cr}$ в структуре $\mathrm{BiFeO}_{3}$ параметр ангармонизма $m$ спиновой волны увеличивается с $0.27 \pm 0.03$ в $\mathrm{BiFeO}_{3}$ до $0.46 \pm 0.03$ в $\mathrm{BiFe}_{0.95} \mathrm{Cr}_{0.05} \mathrm{O}_{3}$ при $T=5.2 \mathrm{~K}$. В этом феррите при повышении температуры параметр ангармонизма $m$ уменьшается от $0.46 \pm 0.03$ при $5.2 \mathrm{~K}$ до $0.29 \pm 0.03$ при $300 \mathrm{~K}$.

Работы, в которых методами мёссбауэровской спектроскопии проводятся температурные исследования мультиферроиков $\mathrm{BiFeO}_{3}$, допированных $s$-, $p$ - и $d$-атомами, в литературе очень мало. Однако такие исследования важны, поскольку позволяют изучить влияние температуры на существование и эволюцию ПСМС, а также на возникающие при этом магнитные фазовые переходы.

Цель данной работы - исследование влияния температуры на магнитную структуру мультифферроика $\mathrm{BiFe}_{0.80} \mathrm{Cr}_{0.20} \mathrm{O}_{3}$ в широкой области температур, включающей температуру магнитного упорядочения, методом мессбауэровской спектроскопии на ядрах ${ }^{57} \mathrm{Fe}$.

\section{2. Образцы и методы исследования}

Образец мультиферроика $\mathrm{BiFe}_{0.80} \mathrm{Cr}_{0.20} \mathrm{O}_{3}$ был приготовлен из стехиометрической смеси $\mathrm{Bi}_{2} \mathrm{O}_{3}$ (чистотой $99.9999 \%$ ), $\mathrm{Fe}_{2} \mathrm{O}_{3}(99.999 \%),{ }^{57} \mathrm{Fe}_{2} \mathrm{O}_{3}$ (с 95.5\% обогащением ${ }^{57} \mathrm{Fe}$ ) в количестве $10 \mathrm{~mol} \%$ и $\mathrm{Cr}_{2} \mathrm{O}_{3}$ (чисто- той 99.99\%). Смесь отжигалась при температуре $1250 \mathrm{~K}$ в течение $1.5 \mathrm{~h}$ при давлении $6 \mathrm{GPa}$ в герметичных золотых капсулах. Затем проводился гомогенизирующий отжиг при $T=800 \mathrm{~K}$ в течение $2 \mathrm{~h}$. После температурного отжига образец медленно охлаждался до комнатной температуры. Рентгенографические измерения выполнены при комнатной температуре на дифрактометре RIGAKU Ultima III в интервале углов дифракции 0-80 с шагом $0.02^{\circ}$ и временем регистрации $6 \mathrm{~s} / \mathrm{step}$.

Мессбауэровские спектры на ядрах ${ }^{57} \mathrm{Fe}$ измеряли в температурном диапазоне $5.2-550 \mathrm{~K}$ с помощью спектрометра MS1104Em в режиме постоянных ускорений с треугольной формой временной зависимости доплеровской скорости движения источника. МС обрабатывались и анализировались методами восстановления распределения сверхтонких параметров мессбауэровского спектра (сверхтонких магнитных полей (СТМП), сдвигов спектров и квадрупольных смещений резонансных линий) и расшифровки спектров в рамках модели ПСМС циклоидного типа, реализованных в программе SpectrRelax $[16,17]$.

\section{3. Экспериментальные данные и их обсуждение}

Рентгеноструктурный анализ образца $\mathrm{BiFe}_{0.80} \mathrm{Cr}_{0.20} \mathrm{O}_{3}$ при комнатной температуре показал, что образец практически однофазный и имеет ромбоэдрическую структуру (пр.гр. $R 3 c$ ). В исследуемых образцах было обнаружено небольшое количество (3-5\%) примесных фаз: $\mathrm{Bi}_{2} \mathrm{O}_{2} \mathrm{CO}_{3}$ и $\mathrm{Fe}_{2} \mathrm{O}_{3}$. Замещение атомов железа на атомы хрома в количестве $20 \mathrm{~mol} \%$ уменьшает параметры решетки от $a=5.5795(1) \AA$ и $c=13.8686(2) \AA$ в $\mathrm{BiFeO}_{3}$ до $a=5.5674(1) \AA$ и $c=13.8130(2) \AA \quad$ в $\mathrm{BiFe}_{0.80} \mathrm{Cr}_{0.20} \mathrm{O}_{3}$. Этот эффект обусловлен тем, что эффективный катионный радиус в октаэдрической кислородной координации трехвалентного катиона хрома $\left(R\left(\mathrm{Cr}^{3+}\right)=0.615 \AA\right)$ значительно меньше эффективного катионного радиуса трехвалентного катиона железа $\left(R\left(\mathrm{Fe}^{3+}\right)=0.645 \AA\right)[18]$.

Для МС мультиферроика $\mathrm{BiFe}_{0.80} \mathrm{Cr}_{0.20} \mathrm{O}_{3}$, полученных ниже температуры Нееля, были восстановлены распределения $p\left(H_{n}\right)$ СТМП $H_{n}$ в предположении о наличии линейной корреляции между всеми сверхтонкими параметрами спектра. В результате анализа восстановленных распределений для исследованного феррита получены температурные зависимости средних значений сверхтонких электрических и магнитных параметров мессбауэровского спектра ядер ${ }^{57} \mathrm{Fe}$.

Обработка температурной зависимости среднего значения СТМП с использованием степенной функции [19] позволила определить температуру Нееля $T_{N}=505 \pm 10 \mathrm{~K}$ и значение критического индекса $\beta=0.33 \pm 0.04$ для ядер ${ }^{57} \mathrm{Fe}$ в $\mathrm{BiFe}_{0.80} \mathrm{Cr}_{0.20} \mathrm{O}_{3}$. Отметим, что при замещении $20 \mathrm{~mol} \%$ атомов железа на атомы хрома температура Нееля $T_{N}$ уменьшилась 
от $T_{N}=633.1 \pm 0.3 \mathrm{~K}$ в $\mathrm{BiFeO}_{3}$ до $T_{N}=505 \pm 10 \mathrm{~K}$ в $\mathrm{BiFe}_{0.80} \mathrm{Cr}_{0.20} \mathrm{O}_{3}$. Эти данные указывают на снижение энергии обменного взаимодействия в цепочках $\mathrm{Fe}-\mathrm{O}-$ $\mathrm{Fe}(\mathrm{Cr})$, когда в ближайшей катионной сфере железа появляются атомы хрома, вероятно, как за счет уменьшения константы косвенного обменного взаимодействия $\mathrm{Fe}-\mathrm{O}-\mathrm{Cr}$, так и за счет меньшей величины локального магнитного момента атома хрома $[20,21]$ по сравнению с локальным магнитным моментом атома железа.

Рассмотрим результаты расшифровки МС-спектров в рамках модели ПСМС циклоидного типа $[3,4]$ в облати температур ниже температуры Нееля. Угол $\vartheta(x)$ между вектором антиферромагнетизма и осью симметрии в структуре феррита висмута $\mathrm{BiFe}_{0.80} \mathrm{Cr}_{0.20} \mathrm{O}_{3}$ в зависимости от координаты $x$ вдоль направления спиновой модуляции и знака коэффициента одноосной магнитной анизотропии представляется уравнениями

$$
\begin{aligned}
& \cos \vartheta(x)=\operatorname{sn}\left(\frac{4 K(m)}{\lambda} x, m\right) \text { при } K_{u}>0, \\
& \cos \vartheta(x)=\operatorname{sn}\left(\frac{4 K(m)}{\lambda} x, m\right) \text { при } K_{u}<0,
\end{aligned}
$$

где $\lambda$ - длина волны спиновой модуляции, $0 \leq m \leq 1-$ параметр (ангармонизма) эллиптической функции Якоби $\operatorname{sn}(x, m), K(m)$ - полный эллиптический интеграл первого рода. Длина волны $\lambda$ спиновой модуляции выражается через энергетические параметры термодинамического потенциала, так называемую обменную жесткость $A$ и константу анизотропии $K_{u}$, характеризующую энергию магнитной анизотропии [22]:

$$
\lambda=4\left(A /\left|K_{u}\right|\right)^{1 / 2} K(m) m^{1 / 2} .
$$

В работах $[5,6]$ было обнаружено, что специфические профили распределения $p\left(H_{n}\right)$ СТМП $H_{n}$ на ядрах ${ }^{57} \mathrm{Fe}$ в феррите $\mathrm{BiFeO}_{3}$, измеренного методом ядерного магнитного резонанса и полученного методом мессбауэровской спектроскопии [8] при расшифровке спектра в рамках модели ПСМС циклоидного типа, совпадают. Это распределение $p\left(H_{n}\right)$ имеет два острых пика по краям и плато между ними. Правый пик соответствует величине поля $H_{\|}$на ядрах атомов железа с ориентацией их магнитных моментов параллельно $(\vartheta=0)$ оси симметрии кристалла, а левый пик - величине поля $H_{\perp}$ на ядрах атомов железа с ориентацией их магнитных моментов перпендикулярно $(\vartheta=\pi / 2)$ оси симметрии кристалла,

Значения СТМП для ориентации магнитного момента атома железа, задаваемого углом $\vartheta$, при малой анизотропии сверхтонкого взаимодействия, как это имеет место в случае ядер ${ }^{57} \mathrm{Fe}$ в $\mathrm{BiFeO}_{3}$, определяются формулой (см. например, $[5,8])$ :

$$
H_{n}(\vartheta(x))=H_{\|}-\left(H_{\|}-H_{\perp}\right) \sin ^{3}(\vartheta(x)),
$$

Это выражение можно записать также в виде [8]:

$$
H_{n}(\vartheta(x))=H_{i s}+H_{a n}\left(3 \cos ^{2}(\vartheta(x))-1\right) / 2,
$$

где $H_{i s}$ - изотропный вклад в СТМП $H_{n}$, определяемый в первую очередь контактным взаимодействием Ферми с локализованными на ядре $s$-электронами, поляризованными спином иона железа, $H_{a n}$ - анизотропный вклад, обусловленный магнитным диполь-дипольным взаимодействием с локализованными магнитными моментами окружающих атомов и анизотропией сверхтонкого магнитного взаимодействия ядра с электронами ионного остова собственного атома. В соответствии с (5): $H_{\|}=H_{i s}+H_{a n}$ и $H_{\perp}=H_{i s}-H_{a n} / 2$.

Мёссбауэровские спектры феррита $\mathrm{BiFe}_{0.80} \mathrm{Cr}_{0.20} \mathrm{O}_{3}$ обрабатывались пятью парциальными спектрами (рис. 1), так как было сделано предположение о наличии пяти наиболее вероятных позиций атома железа, в первой катионной координационной сфере которых расположены $N_{\mathrm{Cr}}=0,1,2,3$ и 4 атома примеси $\mathrm{Cr}$. Для всех парциальных спектров сдвиги, квадрупольные смещения, анизотропные вклады $H_{a n}$ и параметры ангармонизма $m$ принимались одинаковыми, а изотропные вклады $H_{i s}$ - разными. Эти пять парциальных MC (на рис. 1 парциальные спектры показаны внутри экспериментального МС) соответствовали модели единой ангармонической спин-модулированной волны циклоидного типа, в которой принимают участие спины всех атомов железа в исследуемом мультиферроике. Огибающие модельных спектров хорошо соответствуют экспериментальным МС (нормированный функционал хи-квадрат $\left.\chi^{2}=1.0-1.2\right)$ с учетом вкладов двух слабоинтенсивных парциальных спектров примесных фаз. В результате модельной расшифровки МС мультиферроика $\mathrm{BiFe}_{0.80} \mathrm{Cr}_{0.20} \mathrm{O}_{3}$ были найдены для каждого из атомов железа с различным катионным окружением относительные интенсивности их парциальных спектров, значения всех сверхтонких параметров спектра, а также параметр ангармонизма спиновой модуляции $m$.

На рис. 2 приведена зависимость относительных интенсивностей парциальных спектров ядер ${ }^{57} \mathrm{Fe}$ в феррите $\mathrm{BiFe}_{0.80} \mathrm{Cr}_{0.20} \mathrm{O}_{3}$ от числа $N_{\mathrm{Cr}}$ атомов $\mathrm{Cr}$ в ближайшем катионном окружении атома $\mathrm{Fe}$, полученная при комнатной температуре. Эти данные показывают, что в $\mathrm{BiFe}_{0.80} \mathrm{Cr}_{0.20} \mathrm{O}_{3}$ распределение атомов хрома по позициям атома железа в структуре феррита близко к случайному с некоторым предпочтением атомов $\mathrm{Fe}$ иметь в ближайшем катионном окружении атомы Fe. Для повышения точности искомых параметров спектра, снятых при температурах выше и ниже комнатной, относительные интенсивности парциальных спектров задавались такими же, как при комнатной температуре, при которой экспериментальный спектр снимался с повышенным качеством.

На рис. 1 в качестве примера приведены мессбауэровские спектры (МС), измеренные при 5.2, 300, 400 и $450 \mathrm{~K}$, и результаты их расшифровки в рамках модели ангармонической ПСМС циклоидного типа. Для температур 300-400 K наилучшее совпадение экспериментальных и модельных спектров получается при использовании формулы (1). В этой области температур наименьший параметр ангармонизма $m=0.28$ получен при температуре $400 \mathrm{~K}$, при которой спиновая волна 

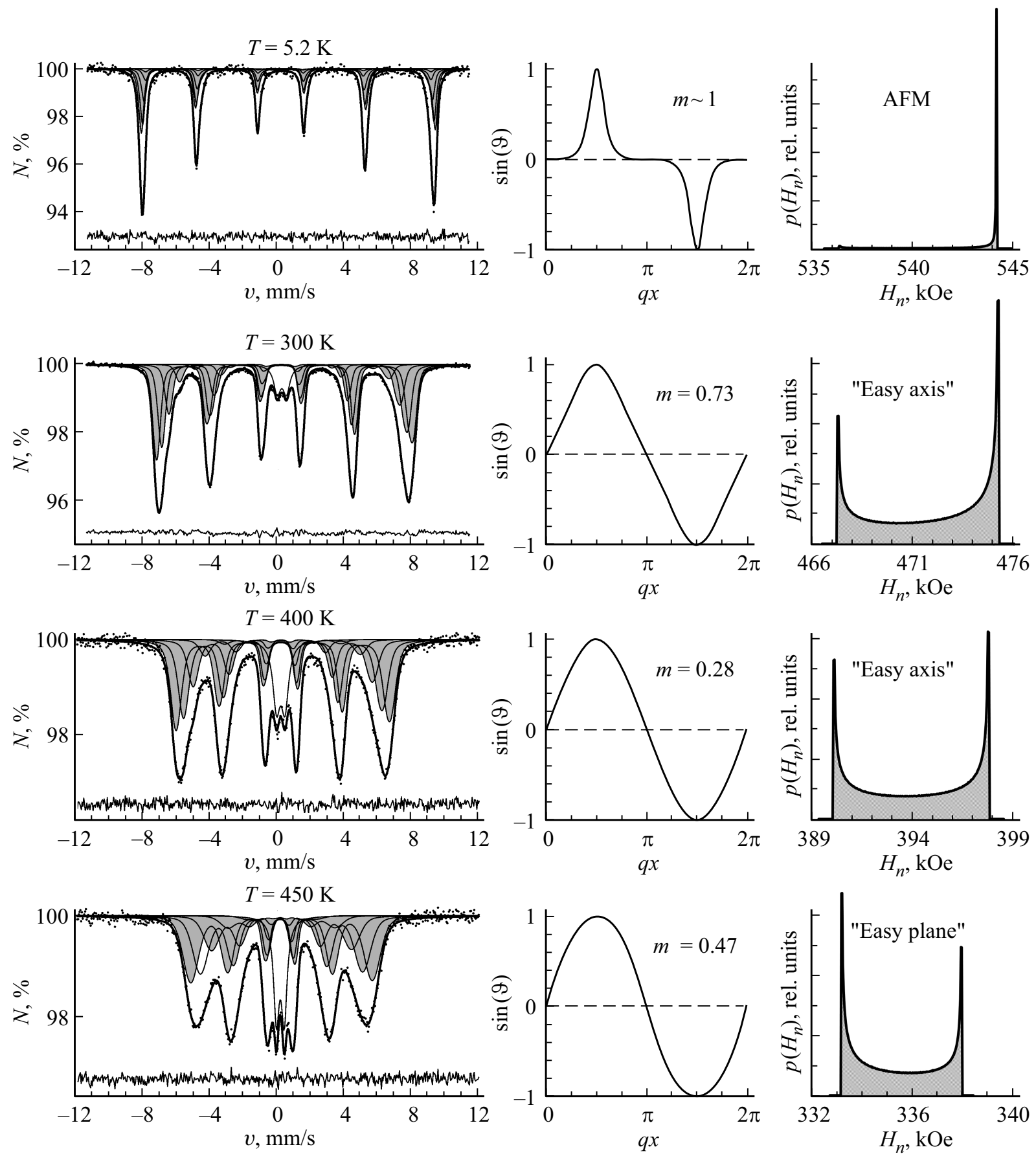

Рис. 1. Мессбауэровские спектры (экспериментальные точки), измеренные при 5.2, 300, 400 и $450 \mathrm{~K}$ (левая колонка), и результаты их расшифровки в рамках модели ангармонической ПСМС циклоидного типа: волны ПСМС в форме функции $\sin (\vartheta(q x))$, где $q=2 \pi / \lambda$ - волновое число ПСМС (средняя колонка), и распределения СТМП $p\left(H_{n}\right)$ для атомов железа, не содержащих в ближайшем катионном окружении атомов хрома, соответствующие функциям $\operatorname{sn}(\vartheta(q x))$ (правая колонка); ломаные линии под спектрами демонстрируют разницу между экспериментальным спектром и огибающей, полученной в результате модельной расшифровки.

является слабо ангармонической (функция $\operatorname{sn}(\vartheta(q x))$ близка к гармонической функции $\sin (q x))$. При понижении температуры в области $300-400 \mathrm{~K}$ ангармонизм спиновой волны значительно увеличивается. Наибольшее значение параметра $m \approx 0.8$ наблюдается при температуре $300 \mathrm{~K}$.
При температурах 300-400 K распределение СТМП $p\left(H_{n}\right)$ содержит два пика разной интенсивности. Интенсивность левого пика меньше интенсивности правого пика (рис. 1). Это означает, что число атомов железа, магнитные моменты которых направлены перпендикулярно оси симметрии кристалла, меньше, 


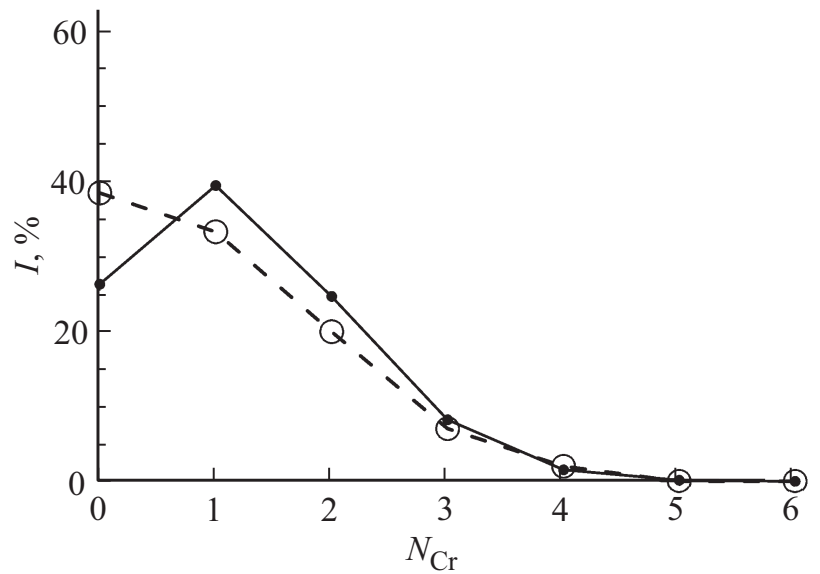

Pис. 2. Зависимость относительных интенсивностей $I$ парциальных спектров ядер ${ }^{57} \mathrm{Fe}$ в феррите $\mathrm{BiFe}_{0.80} \mathrm{Cr}_{0.20} \mathrm{O}_{3}$ от числа $\mathrm{NCr}$ атомов $\mathrm{Cr}$ в ближайшем катионном окружении атома $\mathrm{Fe}$; точки, соединенные линиями - биномиальное распределение $P_{6}\left(N_{\mathrm{Cr}}\right)$.

чем число атомов железа, магнитные моменты которых направлены параллельно оси симметрии кристалла (направлению [001] в гексагональном представлении). С уменьшением температуры относительное количество атомов, у которых магнитные моменты ориентированы перпендикулярно оси симметрии кристалла, уменьшается, а относительное количество атомов с ориентацией моментов вдоль оси симметрии увеличивается. В области температур $<400 \mathrm{~K}$ при понижении температуры параметр ангармонизма $m$ увеличивается и стремится к единице $m \rightarrow 1$. Рост параметра $m$ означает, что константа одноосной магнитной анизотропии $K_{u}$ увеличивается (см. уравнение (3)). В этой области температур константа $K_{u}$ положительная и существует одноосная магнитная анизотропия типа „легкая ось“. При $T \lesssim 260 \mathrm{~K}$ энергия магнитной анизотропии становится большой, сравнимой с обменной энергией, что приводит к разрушению ПСМС и ее трансформации в коллинеарную антиферромагнитную структуру $G$-типа. На рис. 1 представлены спиновая волна и распределение СТМП $p\left(H_{n}\right)$ при $5.2 \mathrm{~K}$. Распределение $p\left(H_{n}\right)$ содержит практически только один пик (правый), указывающий на то, что магнитные моменты атомов железа направлены вдоль легкой оси - оси симметрии кристалла.

В области температур 450-550 K наилучшее совпадение экспериментальных и модельных спектров наблюдается при расшифровке МС в рамках ПСМС циклоидного типа по формуле (2) (константа магнитной анизотропии $\left.K_{u}<0\right)$. В этой области температур наблюдается магнитная анизотропия типа „легкая плоскость“. На рис. 1 в качестве примера для температуры $450 \mathrm{~K}$ представлены экспериментальный МС, а также спиновая волна $\sin (\vartheta(q x))$ и распределение СТМП $p\left(H_{n}\right)$, соответствующие найденному значению параметра ан- гармонизма $m=0.47 \pm 0.09$. Как видим, распределение $p\left(H_{n}\right)$ существенно изменилась. Интенсивность левого пика увеличилась, а интенсивность правого пика стала меньше. Это означает, что число атомов железа с магнитными моментами, направленными перпендикулярно оси симметрии кристалла, стало больше по сравнению с числом магнитных моментов атомов железа, магнитные моменты которых параллельны оси симметрии кристалла. Этот эффект наблюдается в области температур $450-500 \mathrm{~K}$ и обусловлен существованием в этой области температур магнитной анизотропией типа „легкая плоскость“ $\left(K_{u}<0\right)$.

На рис. 3 приведена температурная зависимость параметра ангармонизма $m(T)$, полученная в результате расшифровки спектров в интервале температур $5.2-550 \mathrm{~K}$. Как видим, в интервале температур $T=5.2-260 \mathrm{~K}$ параметр ангармонизма не изменяется и равен $m \approx 1$. В этой области температур существует коллинеарная антиферромагнитная структура $G$-типа. В области температур 260-420 К при повышении температуры параметр ангармонизма стремится к нулю, ПСМС становится более гармонической и при $\sim 420 \mathrm{~K}$ преобразуется в гармоническую циклоиду. В этой области температур существует магнитная анизотропия типа „легкая ось“ $\left(K_{u}>0\right)$. При дальнейшем повышении температуры в области $T=420-550 \mathrm{~K}$, где существует магнитная анизотропия типа „легкая плоскость“, ПСМС становится ангармонической и параметр $m$ увеличивается. В области температуры $\sim 420 \mathrm{~K}$ константа анизотропии $K_{u}$ изменяет знак.

$\mathrm{B}$ мультиферроике $\mathrm{BiFeO}_{3}$ изменение знака эффективной константы магнитной анизотропии $K_{u}$ наблюдается при температуре $\sim 330 \mathrm{~K}[14,15]$. Замещение атомов железа в количестве $20 \mathrm{~mol} \%$ атомов хрома увеличивает температуру изменения знака константы $K_{u}$ до $\sim 420 \mathrm{~K}$. В соответствии с формулой (3) увеличение модуля константы магнитной анизотропии $\left|K_{u}\right|$ и (или) уменьшение обменной жесткости $A$ приводит к увеличению

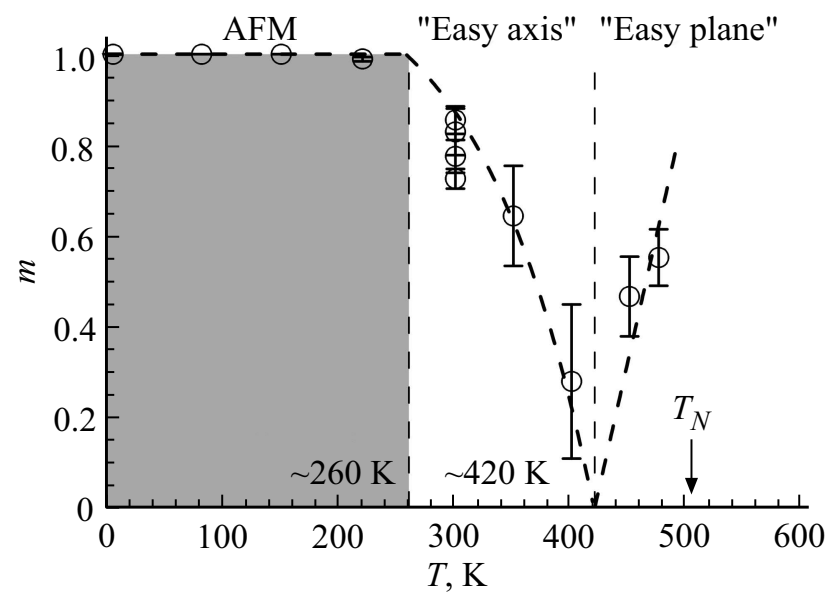

Рис. 3. Температурная зависимость параметра ангармонизма $m(T)$ в мультиферроике $\mathrm{BiFe}_{0.80} \mathrm{Cr}_{0.20} \mathrm{O}_{3}$. 
параметра ангармонизма $m$. Замещение атомов железа атомами хрома в $\mathrm{BiFe}_{0.80} \mathrm{Cr}_{0.20} \mathrm{O}_{3}$ увеличивает параметр ангармонизма $m$ при $300 \mathrm{~K}$ почти в семь раз: для $\mathrm{BiFeO}_{3}$ $m=0.12$ [18], а для $\mathrm{BiFe}_{0.80} \mathrm{Cr}_{0.20} \mathrm{O}_{3} m \sim 0.8$. Константа обменной жесткости пропорциональна температуре Нееля $A \propto T_{N}$. Температура Нееля $T_{N}$ в $\mathrm{BiFeO}_{3}$ равна $633 \mathrm{~K}$, а в $\mathrm{BiFe}_{0.80} \mathrm{Cr}_{0.20} \mathrm{O}_{3}-505 \mathrm{~K}$. Как видим, параметр обменной жесткости $A$ в $\mathrm{BiFe}_{0.80} \mathrm{Cr}_{0.20} \mathrm{O}_{3}$ уменьшается на $\sim 25 \%$ по сравнению с ферритом $\mathrm{BiFeO}_{3}$. Таким образом, основной причиной изменения параметра энгармонизма $m$ является изменение константы анизотропии $K_{u}$. Замещение атомов железа атомами хрома в $\mathrm{BiFe}_{0.80} \mathrm{Cr}_{0.20} \mathrm{O}_{3}$ сильно увеличивает константу одноосной магнитной анизотропии и этот эффект сдвигает температуру изменения знака константы магнитной анизотропии, т.е. температуру компенсации вкладов в эффективную константу магнитной анизотропии, к более высоким температурам.

В работе [15] рассмотрен возможный механизм изменения знака константы магнитной анизотропии в мультиферроике $\mathrm{BiFeO}_{3}$. Предполагалось, что наблюдаемый эффект объясняется конкуренцией различных вкладов в эффективную магнитную анизотропию и их различной зависимостью от температуры в феррите висмута. Один вклад обусловлен одноосной магнитной анизотропией, характерной для коллинеарной антиферромагнитной системы. Другой вклад возникает из-за слабого ферромагнетизма, вызванный взаимодействием ДзялошинскогоМория, который обусловливает скос магнитных подрешеток. Экспериментальные данные, полученные в данной работе, показывают, что в $\mathrm{BiFe}_{0.80} \mathrm{Cr}_{0.20} \mathrm{O}_{3}$ в интервале температур $T=5-420 \mathrm{~K}$ основной вклад в эффективную магнитную анизотропию вносит одноосная магнитная анизотропия типа „легкая ось“ из-за значительного увеличения константы одноосной анизотропии при замещении атомов железа атомами хрома. Замещение атомов железа атомами хрома, вероятно, слабее влияет на константу анизотропии взаимодействия ДзалошинскогоМория. Этот эффект обусловливает сдвиг температуры переключения эффективной константы анизотропии $K_{u}$ в область температур вблизи $420 \mathrm{~K}$. При $T>420 \mathrm{~K}$ основной вклад в эффективную магнитную анизотропию определяется взаимодействием Дзялошинского-Мория.

\section{4. Заключение}

Исследован образец мультиферроика $\mathrm{BiFe}_{0.80} \mathrm{Cr}_{0.20} \mathrm{O}_{3}$, синтезированный методом твердотельного синтеза при высоких давлениях, методом мессбауэровской спектроскопии на ядрах ${ }^{57} \mathrm{Fe}$ в области температур $5.2-550 \mathrm{~K}$. Образец $\mathrm{BiFe}_{0.80} \mathrm{Cr}_{0.20} \mathrm{O}_{3}$ имел ромбоэдрическую структуру $R 3 c$. Определена температура Нееля $T_{N}=505 \pm 10 \mathrm{~K}$. Расшифровка месссбауэровских спектров в рамках модели ПСМС циклоидного типа позволила получить следующие результаты.
В феррите образуется ангармоническая пространственно-модулированная спиновая структура циклоидного типа, в которой участвуют атомы железа с 0, 1, 2, 3 и 4 атомами хрома в ближайшем катионном окружении. Установлено, что в $\mathrm{BiFe}_{0.80} \mathrm{Cr}_{0.20} \mathrm{O}_{3}$ атомы хрома практически случайно распределяются в решетке по позициям атомов железа.

В области температур 5.2-260K параметр ангармонизма $m \approx 1$, ПСМС разрушена и существует коллинеарная антиферромагнитная структура $G$-типа. При увеличении температуры от $260 \mathrm{~K}$ параметр ангармонизма $m$ уменьшается от $\sim 0.8$ при $300 \mathrm{~K}$ до 0.23 при 400 К. В этой области температур существует ангармоническая спиновая волна с магнитной анизотропией типа „легкая ось“ (эффективная константа магнитной анизотропии $K_{u}$ положительна). При $T \sim 420 \mathrm{~K}$ параметр ангармонизма $m=0$ и спиновая волна становится гармонической.

Выше $T \sim 420 \mathrm{~K}$ параметр $m$ снова увеличивается, спиновая волна становится ангармонической с магнитной анизотропией типа „легкая плоскость“ (константа анизотропии $K_{u}$ отрицательна). Изменение знака эффективной константы магнитной анизотропии при $\sim 420 \mathrm{~K}$ объясняется конкуренцией различных вкладов в эффективную магнитную анизотропию и их различной зависимостью от температуры в феррите висмута.

\section{Список литературы}

[1] Ю.Н. Веневцев, В.В. Гагулин, В.Н. Любимов. Сегнетомагнетики. Наука, М. (1982). 224 с.

[2] I. Sosnowska, T. Peterlin-Neumaier, E. Steichele. J. Phys. C 15, 4835 (1982).

[3] I. Sosnowska, A.K. Zvezdin. J. Magn. Magn. Mater. 140-144, 167 (1995)

[4] M.-M. Tehranchi, N.F. Kubrakov, A.K. Zvezdin. Ferroelectrics 204, 181 (1997).

[5] A.V. Zalessky, A.A. Frolov, T.A. Khimich, A.A. Bush, V.S. Pokatilov, A.K. Zvezdin. Europhys. Lett. 50, 547 (2000).

[6] V.S. Pokatilov, A.S. Sigov. J. Exp. Theor. Phys. 110, 440 (2010).

[7] I. Sosnowska, R. Przenioso. Phys. Rev. B 84, 144404 (2011).

[8] В.С. Русаков, В.С. Покатилов, А.С. Сигов, М.Е. Мацнев, Т.В. Губайдулина. Письма ЖЭТФ 100, 518 (2014).

[9] А.К. Звездин, А.П. Пятаков. УФН 174, 65 (2004).

[10] В.С. Русаков, В.С. Покатилов, А.С. Сигов, М.Е. Мацнев, А.М. Гапочка, Т.Ю. Киселева, А.Е. Комаров, М.С. Шатохин, А.О. Макарова. Изв. РАН. Сер. физ. 79, 1097 (2015).

[11] В.С. Русаков, В.С. Покатилов, А.С. Сигов, М.Е. Мацнев, А.М. Гапочка, Т.Ю. Киселева, А.Е. Комаров, М.С. Шатохин, А.О. Макарова. ФТТ 58, 102 (2016).

[12] В.С. Покатилов, В.С. Русаков, А.С. Сигов, А.А. Белик, М.Е. Мацнев, А.Е. Комаров. ФТТ 59, 433 (2017).

[13] В.С. Покатилов, В.С. Русаков, А.С. Сигов, А.А. Белик. ФТТ 59, 1535 (2017)

[14] Vyacheslav Rusakov, Vyacheslav Pokatilov, Alexander Sigov, Mikhail Matsnev, Alexander Pyatakov. EPJ Web Conf. 185, 07010 (2018). 
[15] В.С. Русаков, В.С. Покатилов, А.С. Сигов, М.Е. Мацнев, А.П. Пятаков. ДАН. Физика 480, 657 (2018).

[16] M.E. Matsnev, V.S. Rusakov. AIP Conf. Proc. 1489, 178 (2012).

[17] M.E. Matsnev, V.S. Rusakov. AIP Conf. Proc. 1622, 40 (2014).

[18] R.D. Shannon. Acta Cryst. A 32, 751 (1976).

[19] S.K. Ma. Modern Theory of Critical Phenomena. Reading, MA: Benjamin-Cummings (1976). $561 \mathrm{p}$.

[20] A.A. Belik, S. Iikubo, K. Kodama, N. Igawa, S. Shamoto, E. Takayama-Muromachi. Chem. Mater. 20, 3765 (2008).

[21] C. Darie, C. Goujon, M. Bacia, H. Klein, P. Toulemonde, P. Bordet, E. Syard. Solid State Sci. 12, 660 (2010).

Редактор К.В. Емцев 